REVISTA DE GEOCIÊNCIAS DO NORDESTE

Northeast Geosciences Journal

v. $6, \mathrm{n}^{\circ} 2(2020)$

https://doi.org/10.21680/2447-3359.2020v6n2ID18750

ISSN: 2447-3359

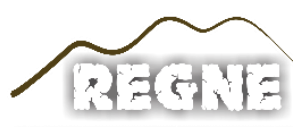

\title{
DELIMITAÇÃO DAS UNIDADES GEOAMBIENTAIS DA GEODIVERSIDADE DO SETOR COSTEIRO SUDESTE DA ILHA DO MARANHÃO, MA- BRASIL
}

\author{
Thiara Oliveira Rabelo ${ }^{1}$; Zuleide Maria Carvalho \\ Lima $^{2}$; Marcos Antônio Leite do Nascimento ${ }^{3}$
}

\author{
${ }^{1}$ Mestre em Goegrafia, Programa de Pós-Graduação em \\ Geografia, Universidade do Rio Grande do Norte (UFRN), \\ Natal/RN, Brasil. \\ ORCID: https://orcid.org/0000-0002-6786-7376 \\ Email: thiarageo@hotmail.com \\ ${ }^{2}$ Doutora em Geodinâmica e Geofísica, Departamento de \\ Geografia, Universidade Federal do Rio Grande do Norte \\ (UFRN), Natal/RN, Brasil. \\ ORCID: https://orcid.org/0000-0002-6971-9801 \\ Email: zcmlima@ hotmail.com \\ ${ }^{3}$ Doutor em Geodinâmica e Geofísica, Departamento de \\ Geologia, Universidade Federal do Rio Grande do Norte (UFRN), \\ Natal/RN, Brasil. \\ ORCID: https://orcid.org/0000-0002-8158-7186 \\ Email: marcos@geologia.ufrn.br
}

\section{Resumo}

A geodiversidade, que corresponde à variedade de elementos como rochas, minerais, feições geomorfológicas e solos, se constitui como parte importante do sistema ambiental. A divisão de unidades geoambientais com base nas características da geodiversidade apresenta-se como ferramenta de pesquisa essencial para conhecer os processos e interações dos elementos abióticos de uma área, como é o caso setor sudeste da Ilha do Maranhão, que apresenta poucos estudos voltados para a sua geodiversidade. O objetivo da pesquisa foi delimitar as principais unidades geomabientais da área com base na geodiversidade local como forma de congregar informações semelhantes sobre os recursos abióticos e de aumentar o conhecimento sobre o mesmo. Utilizando a abordagem geossistêmica e a partir do levantamentos bibliográficos e cartográficos, uso de SIG's e atividades de campo, foi feita a delimitação de três unidades geoambientais deste setor: Tabuleiros costeiros, Planície flúvio-marinha e Planície Costeira. Estima-se que este estudo seja base para próximas pesquisas sobre a temática e para o planejamento e ordenamento territorial da área.
Palavras-chave: Geodiversidade; Unidades Geoambientais; Zona Costeira.

GEOENVIRONMENTAL UNITS DELIMITATION OF GEODIVERSITY OF THE SOUTHEAST COAST SECTOR OF MARANHÃO ISLAND, MA- BRAZIL

\begin{abstract}
Geodiversity, which corresponds to the variety of elements such as rocks, minerals, geomorphological features and soils, constitutes an important part of the environmental system. The division of geoenvironmental units based on the geodiversity characteristics presents itself as an essential research tool to know the processes and interactions of the abiotic elements of an area, as is the case southeast sector of the Island of Maranhão, which presents few studies focused on the its geodiversity. The objective of the research was to delimit the main geomontial units of the area based on local geodiversity as a way to gather similar information about the abiotic resources and to increase the knowledge about the same. Using the geosystemic approach and from the bibliographical and cartographic surveys, the use of GIS and field activities, the delimitation of three geoenvironmental units of this sector was done: Coastal Tabuleiros, Fluvial-Marine Plain and Coastal Plain. It is estimated that this study is the basis for future research on the subject and for the planning and territorial planning of the area.
\end{abstract}

Keywords: Geodiversity; Geoenvironmental Units; Seaside Resort.

DELIMITACIÓN DE UNIDADES GEOAMBIENTALES DE LA GEODIVERSIDAD DEL SECTOR COSTERO SURESTE DE LA ISLA MARANHÃO, MA- BRASIL

\section{Resumen}

La geodiversidad, que corresponde a la variedad de elementos como rocas, minerales, características geomorfológicas y suelos, es una parte importante del sistema ambiental. La división de unidades geoambientales basadas en las características de la geodiversidad se presenta como una herramienta de investigación esencial para comprender los procesos e interacciones de los elementos abióticos de un área, como es el caso del sector sureste de la isla de Maranhão, que presenta pocos estudios centrados en el Su geodiversidad. El objetivo de la investigación fue delimitar 
las principales unidades geoambientales en el área en función de la geodiversidad local como una forma de recopilar información similar sobre los recursos abióticos y aumentar el conocimiento al respecto. Utilizando el enfoque geosistémico y basándose en encuestas bibliográficas y cartográficas, el uso de SIG y actividades de campo, se delimitaron tres unidades geoambientales en este sector: tableros costeros, planicie fluvialmarina y planicie costera. Se estima que este estudio será la base para futuras investigaciones sobre el tema y para la planificación territorial y el ordenamiento del área.

Palabras-clave: Geodiversidad; Unidades geoambientales; Zona costera.

\section{INTRODUÇÃO}

A compreensão dos elementos dentro de um sistema ambiental é fundamental para entender sua dinâmica e suporte a atividades socioeconômicas. A caracterização dos processos geoambientais e das formas de apropriação do homem sobre os elementos naturais é importante para pensarmos em medidas de gestão e conservação destes elementos, no que se refere não apenas a biodiversidade, mas também a geodiversidade.

Autores como Gray (2004), Brilha (2005), Nascimento et al (2008), definem a geodiversidade como a diversidade natural de feições, elementos geológicos (rochas e minerais), geomorfológicos (formas de relevo) e de solos, incluindo suas associações, relações, propriedades, interpretações e sistemas.

Para entender melhor os processos, as interações destes elementos da geodiversidade e seus usos feitos pelo homem, consideramos neste trabalho a divisão de unidades geoambientais com base nas características da geodiversidade como ferramenta de pesquisa essencial para conhecer melhor sobre os processos e interações dos elementos abióticos de uma determinada área, tendo como princípio básico a conectividade entre os elementos defendida pela abordagem geossistêmica, na geografia.

A delimitação de unidades voltadas para a congregação de características abióticas de uma área, pode ser de essencial importância para áreas com poucos estudos voltados para a sua geodiversidade, como é o caso do setor sudeste da Ilha do Maranhão, localizado no Estado do Maranhão. Este setor corresponde a uma área de $74 \mathrm{~km}^{2}$, segundo dados do Projeto GEOILHA (2015-2017) e abrange parte do município de São Luís e de São José de Ribamar. Atualmente, esta região é apontada por autores como Reis (2005) e Lago (2012) como um dos setores de expansão urbana da Ilha e não possuem muitos estudos relacionados á sua geodiversidade que venham a subsidiar futuras ações de planejamento e gestão desta área.

A referida área (Figura 01) conta com um ambiente costeiro de dinâmica peculiar, apresentando feições como planícies flúviomarinhas, tabuleiros, falésias, praias arenosas, que possuem acentuado potencial paisagístico e são de suma importância para as populações localizadas nestas áreas, que vivem de atividades econômicas relacionadas à agricultura e extração mineral, que fazem uso direto do potencial da geodiversidade.

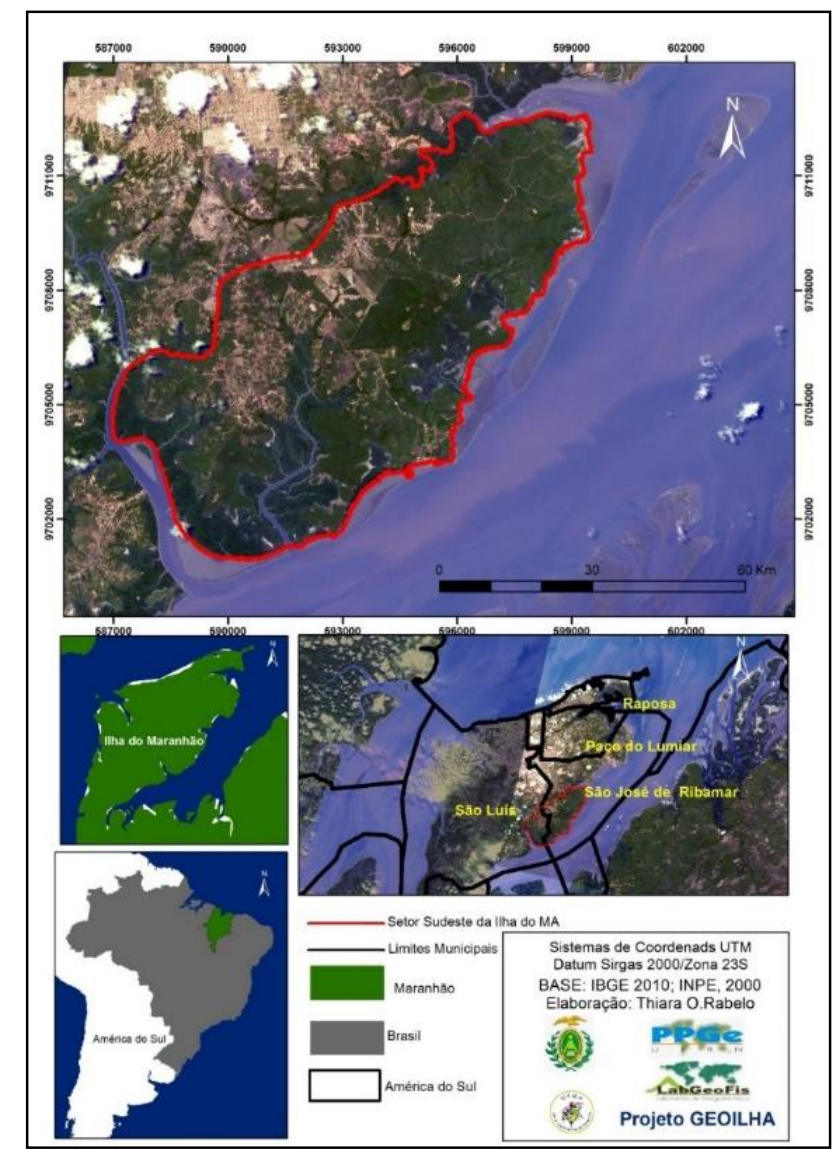

Figura 1 - Localização do setor costeiro sudeste da Ilha do Maranhão. Fonte: Rabelo (2018)

Desta forma, o objetivo deste trabalho foi delimitar as principais unidades geoambientais do setor sudeste da Ilha do Maranhão com base na geodiversidade local como forma de congregar informações semelhantes sobre os recursos abióticos da área, a partir da compreensão de suas interações e processos, que venham servir como base para futuros pesquisas sobre esta área e para o planejamento e gestão destes recursos neste setor.

\section{METODOLOGIA}

Esta pesquisa está fundamentada na concepção da abordagem geossistêmica (Sotchava,1977; Bertrand, 1997; Ross, 2006;) que tem como base a Teoria Geral dos Sistemas criada por Bertalanffy em 1973. Para alcance do objetivo do trabalho a pesquisa foi desenvolvida seguindo as principais etapas metodológicas a seguir:

$\checkmark$ Levantamentos de informações bibliográficas e documentais que abordem de forma direta ou indireta a geodiversidade da área de estudo como as pesquisas de Silva (1973), Feitosa (2006), Klein e Souza (2012), Silva (2012); Bandeira (2013).

$\checkmark \quad$ Levantamento de materiais cartográficos da área e compatibilização de cartas DSG, imagens do Google Earth e imagens de satélite LANDSAT 8 OLI do ano de 2016 
disponibilizadas pelo INPE, e dados vetoriais referentes a geodiversidade do Estado do Maranhão, disponibilizados pela CPRM (2013), para maior detalhamento e compreensão da geodiversidade local.

$\checkmark$ Uso de técnicas de sensoriamento remoto e Geoprocessamento que vieram a auxiliar na identificação de tipologias geológicas e feições geomorfológicas diferenciadas, assim como para apontamentos de uso destes recursos a partir das ações humanas, assim como para associação destas informações com informações adquiridas a partir de atividades de campo e posteriormente a delimitação espacial das unidades geomabientais.

$\checkmark \quad$ Atividades de campo para validação dos dados secundários utilizados na pesquisa e análise das características da geodiversidade da área in loco, onde o principal objetivo foi a observação da paisagem a fim de perceber as implicações mais visíveis na área de estudo decorrente das formas de uso dos elementos abióticos na área.

A partir destas etapas foi a análise e interpretação das informações levantadas, definida a delimitação e descrição das unidades geoambientais do setor sudeste da Ilha do Maranhão com base nas características da geodiversidade e nas correlações de uso das comunidades sobre os recursos abióticos.

\section{RESULTADOS E DISCUSSÃO}

\subsection{A geodiversidade do setor sudeste costeiro da Ilha do Maranhão}

No que se refere a geodiversidade da área, podemos destacar que a geologia deste setor é compreendida em maior parte pelos sedimentos da Formação Barreiras que é litogicamente formada por "arenitos mal selecionados, finos a grossos, variegados, em geral argilosos e com numerosas intercalações de folhelhos" (AGUIAR, 1971.). Também ocorre a presença de depósitos de pântanos e mangue que, segundo Rodrigues et al (1994) são constituídos por sedimentos lamosos (argila e silte), de coloração cinza, não adensados, maciços e biopertubados.

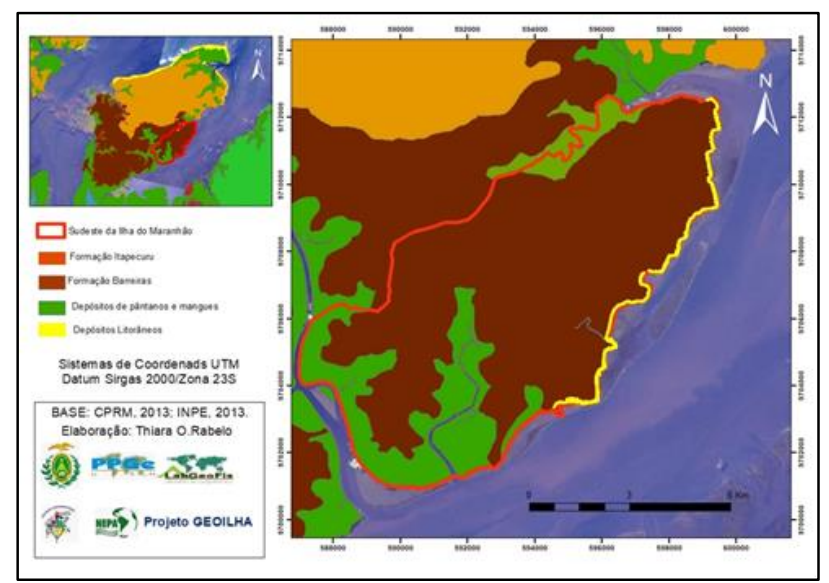

Figura 02 - Unidades geológicas presentes no setor costeiro sudeste da Ilha do Maranhão. Fonte: Rabelo (2018)
Embora não estejam presentes nos grandes mapeamentos feitos para o Estado do Maranhão, Rabelo et al (2016) destacam que os depósitos litorâneos também estão presentes nesta área na forma de areias quartzosas de granulometria média a muito fina.

Em relação a Geomorfologia, a CPRM (2013) destaca para este setor a presença de: Tabuleiros Dissecados, Planícies FlúvioMarinhas e Planícies Fluviais. Os tabuleiros dissecados correspondem a maior parte da área em questão e segundo a CPRM (2013), estão esculpidos em baixos platôs dissecados e colinas tabulares, entalhados por uma rede de canais de densidade de drenagem moderada. (Figura 03)

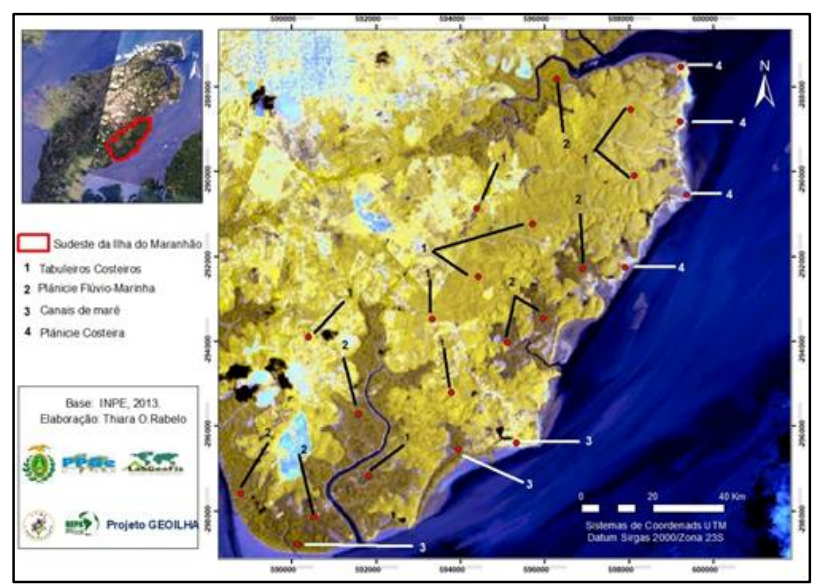

Figura 03 -Principais feições geomorfológicas do setor costeiro sudeste da Ilha do Maranhão. Fonte: Rabelo et al, (2018).

Rabelo et al (2016), destacam que estes tabuleiros se encerram sob a forma de falésias presentes na área de estudo, como é o caso das praias de Guarapiranguinha e Praia de Catatiua. A Planície Flúvio-Marinha é formada por zonas estuarinas das redes de drenagem desta área, sendo mais representativas nas proximidades do rio Tibiri e Tijupá, e é caracterizada pelo predomínio de mangues, superfícies planas e zona de contato entre os sistemas deposicionais continentais e marinhos estão associadas aos canais de maré.

A planície costeira desta área é de menor extensão se comparadas quanto às planícies costeiras do litoral ocidental da Ilha do Maranhão, mas possuem imenso potencial paisagístico e são de suma relevância para a dinâmica ambiental da área de estudo.

Quanto a pedologia, de acordo com os dados do mapeamento feito pela CPRM (2013) neste setor estão presentes os argissolos vermelhos amarelos, os latossolos amarelos e os solos indiscriminados de mangue. Os argissolos vermelho-amarelos (Figura 4), segundo Silva (2012), não são hidromórficos e são pouco profundos, bem drenados e em geral apresentam forte limitações ao manejo e mecanização agrícola devido à quantidade de laterita na superfície e no interior dos seus perfis. Já os latossolos amarelos apresentam boas condições físicas de retenção de umidade e boa permeabilidade e notamos sua presença nas partes de relevo plano, com suaves ondulações, como é o caso das áreas tabulares do setor sudeste da Ilha. 


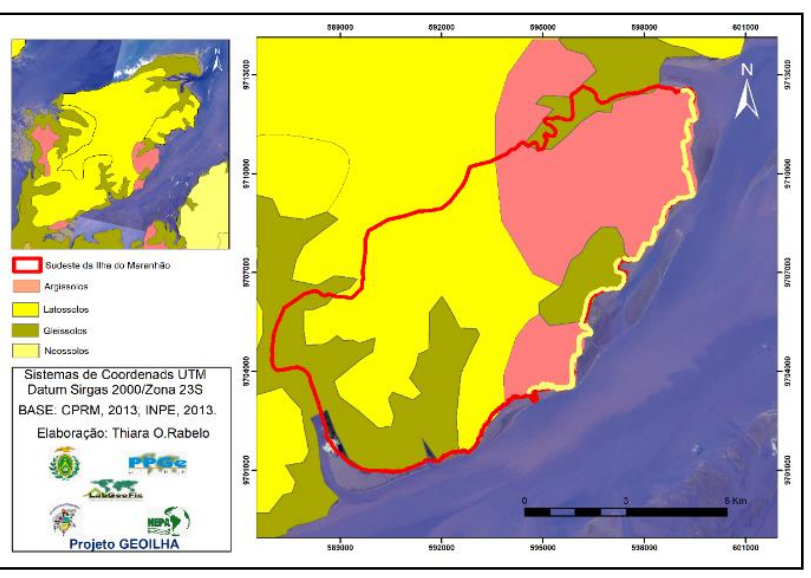

Figura 4 - Unidades pedológicas presentes no setor sudeste da Ilha do Maranhão. Fonte: Rabelo (2018)

Os gleissolos estão presentes em todos as áreas mais planas relacionadas as planícies fluviomarinhas e de acordo com Silva (2012), contem altos teores de compostos de enxofre, em virtude das mudanças do nível da água pelas marés e com o processo de oxidação, tornam-se mais ácidos. Silva (2012) também destaca nesta área a presença de neossolos quartzarênicos órticos alúminicos, que ocorrem em pequenas manchas na área em toda a planície costeira.

No que se refere aos principais tipos de uso da geodiversidade na área destacamos a agricultura, que apresenta-se como atividade econômica de maior destaque na área; a extração mineral, que ocorre principalmente sob forma da extração de areia e recursos latéríticos para construção civil; e a atividade turística, que mesmo que seja incipiente ainda neste setor da Ilha do Maranhão, o potencial paisagístico das praias desta área já chamam atenção de visitantes. As Pontas de Guarapiranga e Juçatuba, sendo a primeira composta pelas praias de Guarapiranga e Guarapiranguinha e a segunda tendo como principal atrativo a Praia de Juçatuba, são os pontos de maior visitação por turistas neste setor.

\subsection{Processos e interações}

Os elementos inseridos em um sistema, sejam eles de ordem natural ou a partir das ações humanas, interagem entre si, e participam de processos que são essenciais na dinâmica de um ambiente. Quando esta dinâmica, se refere a sistemas costeiros, sabemos que se tratam de processos e interações bem mais frágeis visto que estas áreas encontram-se em ambientes de transição entre o mar e o continente.

Christofolletti (1982), infere que os processos costeiros resultam da interação de fatores geológicos (forma e resistência a erosão), climáticos (ação dos processos físico, químicos e biológicos), fatores bióticos (os organismos podem apresentar consequências erosivas, escavando e promovendo desagregação dos minerais das rochas, ou protetoras e construtivas, facilitando a retenção dos sedimentos e o acúmulo de detritos), ventos (geração de ondas e correntes) e oceanográficos (natureza da água do mar, apresentando variações na salinidade).

Nesse contexto, embora ainda seja escasso os dados climáticos e oceanográficos mais pontuais sobre este setor costeiro da Ilha do Maranhão, é possível observar que a localização geográfica desta área implica em mudanças na dinâmica deste ambiente, visto que a menor intensidade de ondas e ventos influenciam na presença de terrações de abrasão mais extensos na área, por exemplo. Porém, Silva (2012), aponta em seu estudo a atuação de ondas e correntes litorâneas nas planícies costeiras do setor sudeste estão indicando pontos de erosão na área.

Já no que se refere ao regime de marés, este setor está localizado na zona de embocadura da Baía de São José, que segundo Coutinho e Morais (1976) possui a ação marinha como processo predominante na área. Silva (2012), ressalta que a Ilha do Maranhão, por ser uma área de macromarés, ou seja, que apresenta amplitudes superiores a 4 metros, apresenta extensas áreas cobertas por planícies de maré, sendo o Sudeste da Ilha um destes locais.

Diversos fatores relacionados principalmente, a sua localização geográfica próxima a Baia de São José, fazem com que esta área seja mais protegida a ação das ondas e se torne propícia para formação de manguezais que estão situados próximos aos estuários dos rios do setor Sudeste.

Porém, em alguns pontos mais distantes da embocadura da Baía de São José (Figura 5) e onde já é possível sentir mais forte a atuação dos ventos no sentido Leste-Oeste que atuam na região do Golfão Maranhense, segundo MUEHE (2006), é possível perceber sua influência na acentuação da dinâmica das ondas.

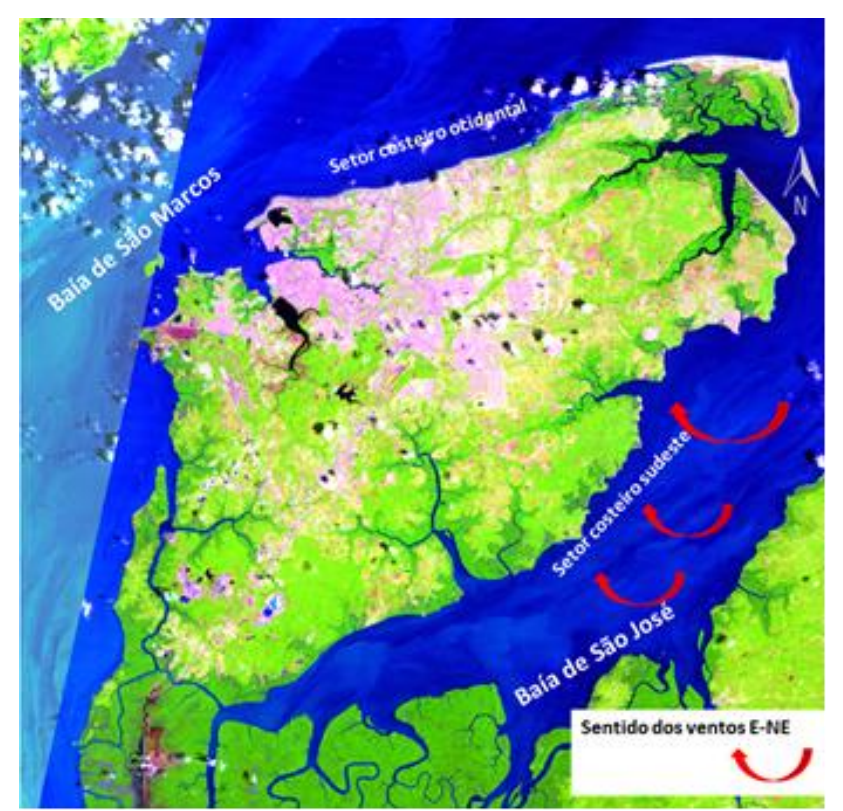

Figura 5 - Localização da Baía de São José mostrando a proximidade com o setor sudeste da Ilha do Maranhão. Fonte: Rabelo (2018).

Na Ponta de Guarapiranga, podemos ver esta situação, citado ainda por Silva (2012), que diz que este é um dos pontos da Ilha onde está havendo recuo de falésias devido a ação das ondas na área, onde em vários pontos do setor Sudeste é possível observar a presença de sedimentos erodidos e retrabalhados pela ação dos 
ventos nos terraços de abrasão da área, oriundos das falésias daquele ambiente.

É importante considerar ainda a afirmação de Popp (2010), de que a velocidade da erosão da rocha é variável, dependendo principalmente do seu tamanho e resistência. Esta interação pode ser percebida na planície costeira do setor Sudeste, visto que há a presença de camadas litológicas paralelas a linha de costa, que contribuem para a formação de plataformas de abrasão e modificam a energia das ondas, diminuindo assim, os processos de erosão costeira nestes pontos.

É importante também ressaltar a interação entre os processos sociais e os costeiros, visto que os seres humanos sempre deram preferência à fixação de assentamentos próximos aos ambientes de rios e praias. Este aspecto é de suma importância para o entendimento dos processos da dinâmica destes ambientes.

No setor Sudeste da Ilha do Maranhão, grande parte de suas comunidades estão assentadas próximas a rios e praias. Verificamos que a interferência antrópica na área, em um contexto geral, não é acentuada e ainda não causa impactos negativos irreversíveis na área, o homem ainda não é considerado uma grande ameaça ao ambiente deste setor.

Embora as principais atividades econômicas que ocorrem nesta região, ligadas diretamente a geodiversidade (agricultura, extração mineral e o geoturismo), não apresentem tantos impactos negativos ainda para área, entretanto seu desenvolvimento já está se dando sem planejamento adequado. E podem acarretar, futuramente, em situações de degradação destes ambientes, devido principalmente ao grande aumento populacional (Quadro 01) que está ocorrendo neste setor, dados que podem sem comprovados pelos dados do censo do IBGE que no ano 2000 era de 107.384 habitantes e no último censo do IBGE em 2010 apresentou uma população de 163.045 habitantes.

Quadro 01 - Crescimento populacional dos munícipios da Ilha do Maranhão. Fonte: Rabelo (2018)

\begin{tabular}{||c||c|c||}
\hline \multirow{2}{*}{ Munícipio } & \multicolumn{2}{|c||}{ População } \\
\cline { 2 - 3 } & $\mathbf{2 0 0 0}$ & $\mathbf{2 0 1 0}$ \\
\hline \hline São Luís & 870.028 & 1.014 .837 \\
\hline \hline São José de Ribamar & 107.384 & 163.045 \\
\hline \hline Paço do Lumiar & 76.188 & 105.121 \\
\hline \hline Raposa & 17.088 & 26.327 \\
\hline
\end{tabular}

A exemplo disto, citamos alguns pontos localizados nas áreas de tabuleiros, onde se localizam algumas comunidades recentes, como o Assentamento Conceição, onde podemos observar alguns pontos próximos destinados ao descarte de lixo. Estes locais ainda não dispõem de políticas públicas relacionadas a coleta de resíduos sólidos, e que podem acarretar em problemas relacionados a poluição do solo ou de aquíferos, comprometendo ainda a saúde da população do local.

Compreender as correlações entre os elementos de um sistema é essencial para perceber, segundo Magalhães e Silva (2010), como se dá o processo de (re) formação espacial e paisagística que constituem o território; e a compreensão destes elementos dentro de um sistema ambiental, é fundamental para entender sua dinâmica e o suporte às atividades socioeconômicas.

\subsection{Unidades geoambientais da geodiversidade}

Levando em consideração as características da geodiversidade, os principais tipos de usos destes recursos, seus processos e interações foi possível congregar estas informações e delimitar as principais unidades geoambientais da geodiversidade do setor costeiro sudeste da Ilha do Maranhão.

Embora entenda-se que as unidade geoambientais fazem parte de uma visão geográfica holística que envolvem tanto as características do meio biótico e abiótico, é importante ressaltar que esta divisão de unidades geoambientais da geodiversidade neste trabalho foi feita baseada na metodologia de mapeamento e divisão de unidades geológico-ambientais ou geoambientais, proposta pela CPRM (2010) e já aplicada já em vários volumes compartimentados para os estados brasileiros (BANDEIRA, 2013; BRANDÃO E FREITAS (2014); ADAMY (2015); onde o foco maior é dado as características da geodiversidade das unidades delimitadas associando as suas potencialidades e limitações de uso.

As unidades geoambientais da geodiversidade que foram delimitadas tendo como ponto principal de partida a geomorfologia, elemento da geodiversidade de maior destaque na área. Sendo assim, foram delimitadas três unidades geoambientais: tabuleiros costeiros, planícies flúvio-marinhas e planície costeira (Figura 6).

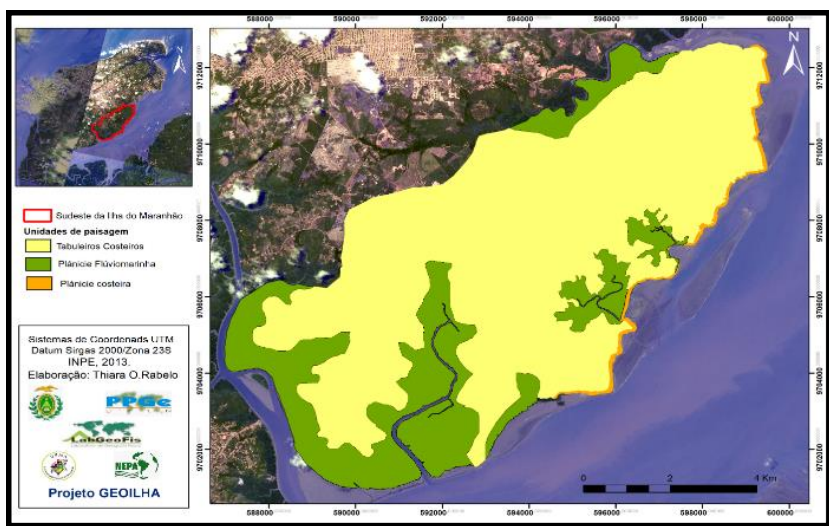

Figura 06 - Delimitação de unidades geoambientais do setor sudeste costeiro da Ilha do Maranhão. Fonte: Rabelo (2018).

\section{A)Tabuleiros Costeiros}

Esta unidade está associada principalmente a Formação Barreiras, e segundo o relatório de geodiversidade da CPRM (2013), esta área compreende principalmente de depósitos arenoargilosos, muito intemperizados e em alguns pontos muito ferriginizados e laterizados.

O relevo desta área está associado a áreas tabulares que correspondem a tabuleiros e tabuleiros dissecados, segundo a classificação da CPRM (2013), recobertos principalmente, por solos do tipo latossolos que apresentam, segundo as informações 
disponíveis no site da EMBRAPA, boas condições físicas de retenção de umidade e boa permeabilidade, sendo intensivamente utilizados para culturas, como é o caso da mandioca naquela região.

Os argissolos, também se encontram presente nesta unidade, e também são solos desenvolvidos a partir do da Formação Barreiras e que possuem boa capacidade para reter nutrientes e armazenar água. Nos locais de ocorrência destes solos, foi observado algumas áreas de escavações de açude (Figura 33) que associados ao relevo tabular, torna-se facilmente escavável, por não precisar de cortes profundos para minimizar seus declives, segundo Bandeira (2013).

Estes Tabuleiros Costeiros se configuram sob formas de relevo suavemente dissecadas que se encerram, por vezes, de forma abrupta sob forma falésias e paleofalésias que podem ser encontradas em vários pontos do setor Sudeste, já em contato com a planície costeira como na Ponta de Guarapiranga, Satuba, Praia da Moça.

A partir das observações feitas em campo e das informações extraídas do relatório de geodiversidade do Estado do Maranhão (BANDEIRA, 2013), esta unidade apresenta potencial para a:

$\checkmark \quad$ Construção de obras de engenharia, visto que apresenta facilidade de escavamento, sem necessidade de cortes profundos para minimizar declives;

$\checkmark \quad$ Média a alta capacidade de suporte;

$\checkmark \quad$ Potencial para exploração de areia, argila e concreções laterírticas para construção civil;

$\checkmark \quad$ Capacidade de armazenamento de água com boa qualidade físico-química;

$\checkmark \quad$ Presença de solos profundos e permeáveis, ácidos e com baixa capacidade de fertilidade natural, passíveis a mecanização e correções a partir de fertilizantes;

E ainda apresenta potencial para:

$\checkmark \quad$ Os tabuleiros que se encerram por meio de falésias possuem acentuado potencial paisagístico o que potencializa o desenvolvimento do geoturismo na área.

$\checkmark \quad$ Exploração de areia, argila e concreções laterírticas para construção civil;

\section{B)Planícies Flúvio-Marinhas}

Esta unidade encontra-se associada principalmente aos Domínios de Pantânos e Mangues com depósitos argiloarenosos, que segundo a CPRM (2012) são constituídos por areias e lamas com restos orgânicos vegetais, apresentando áreas com cascalhos e areias médias e finas, devido a sedimentação fluvial. Segundo Rodrigues et al. (1994), estes depósitos são constituídos, predominantemente, por sedimentos lamosos (argila e silte), de coloração cinza, não adensados, maciços e bioturbados.

Encontra-se localizada nas superfícies mais aplainadas próximos aos cursos hídricos deste setor. Esta área compreende zonas estuarinas das redes de drenagem das bacias hidrográficas, área de contanto entre os sistemas deposicionais continentais e marinhos, com influência da maré e com predomínio de mangues.

Estas áreas de superfícies mais aplainadas são recobertas por gleissolos, que quando estão alagados, possuem algumas restrições a agricultura. Mas em épocas de estiagem, apresentam aptidão para produção de produtos irrigados. Algumas plantações de cooperativas de agricultores do setor sudeste encontram-se situadas dentro desta unidade, como é o caso da comunidade e Coquilho II.

Vale destacar, que nesta unidade estão localizados os principais rios desta parte da Ilha, que dão suporte para sobrevivência de muitas comunidades ribeirinhas locais, não só através da extração animal, mas também muitos utilizam daquelas águas para suas necessidades diárias e utilizam os rios para momentos de lazer (Figura 36).

De acordo com Bandeira (2013), e com as observações feitas durante as atividades de campo, a geodiversidade desta unidade apresenta principalmente as seguintes potencialidades:

$\checkmark \quad$ Em alguns pontos apresenta em subsuperficie camadas arenosas com potencial aquífero. Porém, encontram-se descontinuas com poucos metros de espessura, o que diminui o potencial do aquífero;

$\checkmark \quad$ Solos alagados com limitações para a agricultura e apresentam aptidões para plantações irrigada.

E ainda apresenta potencialidades como:

$\checkmark \quad$ Ambiente geológico favorável para a ocorrência de argilas para fabricação de cerâmicas;

$\checkmark \quad$ Áreas de rios e mangues com potencial paisagístico proeminente para o desenvolvimento de geoturismo.

\section{C)Planície Costeira}

Esta unidade está diretamente associada aos depósitos litorâneos que ocorrem na Ilha do Maranhão. Muehe (2006), afirma que as planícies costeiras do Maranhão são caracterizadas por uma dinâmica significativa, sobretudo, por trata-se de uma costa transgressiva dominada por macromaré.

A unidade está localizada próximo a foz da Baía de São José e segundo Muehe (2006), nesta área ocorrem "extremidades de esporões ou de bancos de areia assimétricos com direção ENWWSW, oblíqua a costa, separados por canais estreitos. Alguns bancos de areia, situados pouco mais a leste orientam-se paralelamente a linha de costa".

A Planície Costeira, encontra-se associada as áreas mais planas próximas ao mar, e ocorrem onde podemos observar ambientes de praias e terraços de abrasão, que possuem contato direto com as falésias, e que estão associadas aos tabuleiros e áreas com resquícios de mangue dominantes na planície flúviomarinha.

A partir das observações feitas em campo, podemos destacar que praias da planície costeira do setor Sudeste da Ilha do Maranhão são predominantemente constituídas por areias quartzosas, associadas a alguns fragmentos de conchas e restos vegetais e arenitos ferruginosos. Cabe aqui as observações feitas por Muehe (2006) sobre as praias-barreiras do litoral maranhense que margeiam áreas de manguezais e são dominadas pelos processos de macro-maré semidiurna, sendo "as praias-barreiras constituídas essencialmente por cordões arenosos lineares constituídos, principalmente por areias quartzosas unimodais finas, de coloração cinza a clara esbranquiçada, bem selecionadas, com fragmentos de conchas, plantas e outros organismos".

Ressaltamos que nesta unidade concentra-se já muitas construções referentes a segundas residências, sendo uma região que aos poucos está se tornando cada vez mais atrativa para a construção de mais casas e estabelecimentos nesta área. Porém, é necessário enfatizar as observações feitas por Bandeira (2013), de 
que os sedimentos deste ambiente são pouco consolidados, com baixa capacidade de suporte, tornando-se limitado para ocupações urbanas.

A partir das observações feitas em campo na área correspondente a esta unidade neste setor, e de acordo com os dados extraídos do relatório de geodiversidade de Bandeira (2013), esta unidade apresenta especialmente as seguintes potencialidades:

$\checkmark \quad$ Compreende aquíferos superficiais com alto potencial para águas subterrâneas, com condições de atender demandas significativas por meios de poços tubulares de grande diâmetro;

$\checkmark \quad$ Apresentam potencial para explotação de baixo custo, por meio de poços escavados e cacimbas para o atendimento a demandas familiares;

Ou ainda apresenta:

$\checkmark \quad$ Elevado potencial paisagístico encontrado em suas praias, com algumas características diferenciadas encontradas no litoral ocidental da Ilha do Maranhão. O que potencializa de forma acentuada o desenvolvimento do geoturismo nesta unidade.

\section{CONSIDERAÇÕES FINAIS}

Os levantamentos feitos sobre a geodiversidade do setor sudeste da Ilha do Maranhão são incipientes de comparados as demais áreas da Ilha do Maranhão. O esforço de pesquisas voltadas para o conhecimento das características da geodiversidade deste setor é de suma importância para a gestão destes recursos na área, visto que é considerada uma das zonas de expansão urbana da Ilha, portanto, a conservação dos sistemas ambientais ali presentes devem ser consideradas.

A divisão das unidades de geoambientais deste setor com base nas características da geodiversidade foi importante para entender as relações que envolvem os elementos abióticos da área e para identificar as potencialidades de cada unidade para o desenvolvimento das atividades humanas e identificação de sua importância para as comunidades da área. O que contribui diretamente para o planejamento, gestão e conservação da geodiversidade local.

Pesquisas voltadas para divisão de unidades geomabientais ainda são pouco utilizadas nos estudos sobre geodiversidade. Compreender estas características a partir da delimitação de unidades geoambientais é importante para os estudos desta temática, devido a possibilidade de congregar as informações semelhantes dos recursos abióticos de uma determinada área em grandes grupos. Além de, entender os principais processos e interações entre estes elementos e sua influência com as atividades humanas e os elementos bióticos, como foi possível constatar no setor costeiro sudeste da Ilha do Maranhão.

\section{REFERÊNCIAS}

ADAMY, A. Geodiversidade do Estado do Acre. Porto Velho: CPRM, 2015. ALMEIDA, F. F. M.; HASUI, Y. BRITO NEVES,B. B.; FUCK, R. A. Províncias Estruturais Brasileiras. In: SBG, Simpósio de Geologia do Nordeste, 8, Campina Grande. Boletim Resumos, 6: 363 - 391. 1977.

BANDEIRA, I.C.N. Geodiversidade do Estado do Maranhão. Teresina: CPRM, 2013.
BERTRAND., G. Paisagem e Geografia Física Global: ensaio metodológico. Caderno de Ciências. São Paula.USP. 1971.

BERTAlAnFFY, L. V. Teoria Geral dos Sistemas. Trad. Francisco Guimarães. Petrópolis, Vozes, 1973.

BRANDÃO, R. de L. e FREITAS, L. C. B. Geodiversidade do Estado do Ceará. Fortaleza: CPRM, 2014.

BRILHA, J. Patrimônio Geológico e Geoconservação: a conservação da natureza na sua vertente geológica. Braga, Palimage. 2005.

COUTINHO, P. da N. e MORAIS, J. O. de. Distribuição de sedimentos na Baía de São José, Estado do Maranhão (Brasil). Revista Ciências Marinhas. Vol. 16. N. 2. 1976.

CHRISTOFOLETTI, Antonio. In: CHRISTOFOLETTI, Antonio (Org). Perspectivas da Geografia. São Paulo: Difel, 1982.

DANTAS, M.E. et al. Compartimentação geomorfológica do Estado do Maranhão. In: Bandeira, I.C.N. Geodiversidade do Estado do Maranhão. Teresina: CPRM. 2013.

FEITOSA. A.C. Relevo do Estado do Maranhão: uma nova proposta de classificação topomorfológica. VI Simpósio Nacional de Geomorfologia. Goiânia. Setembro/2006.

GRAY, M. Geodiversity: valuing and conserving abiotic nature. Wiley. Chichester. $1^{\circ}$ edição. 2004.

IBGE. Instituto Brasileiro de Geografia e Estatística. IBGE cidades. 2010. Disponível em: https://cidades.ibge.gov.br/

IBGE. Instituto Brasileiro de Geografia e Estatística. IBGE cidades. 2000. Disponível: https://cidades.ibge.gov.br/.

IBGE. Instituto Brasileiro de Geografia e Estatística. Limites municipais. 2010. Disponível em: https://mapas.ibge.gov.br/bases-e-referenciais/basescartograficas/mapas-municipais.html.

INPE. Instituto Nacional de Pesquisas Espaciais. Catálogo de Imagens. 2013. Disponível em: http://www.dgi.inpe.br/CDSR/.

KLEIN, E.L. e SOUSA, C.S. Geologia e Recursos Minerais do Estado do Maranhão. Escala 1:750.000, CPRM. Belém, 2012.

LAGO, F.B. Metropolização e Gestão Urbana na Ilha do Maranhão: efeitos socioambientais da produção imobiliária de baixa renda. Revistas de Políticas Públicas. UFMA. Outubro. 2012.

MUEHE, D. (Org.) GERCO - Gerenciamento Costeiro do Estado do Maranhão. Secretaria de Estado do Meio Ambiente e Recursos Hídricos. Coordenadoria de Programas Especiais. Programa Estadual de Gerenciamento Costeiro. Macrozoneamento do Golfão Maranhense. 2006. 
NASCIMENTO, M.A.L. do et al. Geodiversidade, Geoconservação e Geoturismo: trinômio importante para a conservação do patrimônio geológico. UFRN/Biblioteca Central Zila Mamede. 2008.

POPP, José Henrique. Geologia Geral. Rio de Janeiro, LTC, 2010.

PROJETO GEOILHA. Geoprocesssamento e Sensoriamento Remoto aplicados ao mapeamento do setor costeiro sudeste da Ilha do Maranhão. Coordenador: Ulisses Denache Vieira Souza. COLUN-UFMA. 2015-2017.

RABELO, T,O. et al. Caracterização da Geodiversidade do setor sudeste da Ilha do Maranhão como subsídio para o planejamento ambiental. IV Simpósio Brasileiro de Patrimônio Geológico. Ponta Grossa. 2017. Disponível em: https://www.4sbpg.com/anais.

RABELO, T.O., SANTOS. N.M., SOUZA, U.D.V. Geotecnologias e Geodiversidade: identificação das feições geomorfológicas do setor costeiro sudeste da Ilha do Maranhão, MA-Brasil. Apresentado no II Workshop do Núcleo de Estudos e Pesquisas Ambientais e IV Workshop de Geotecnologias do Maranhão. UFMA. 2018.

REIS, R. de J. dos. Costa Sudeste do município de São Luís - MA: Análise e proposta para Gestão Ambiental. Dissertação apresentada ao Curso de Mestrado em Gestão Políticas Ambientais. Universidade Federal do Pernambuco. Recife. UFPE. 2005.

RIBEIRO, N. dos R. et al. Geodiversidade e potencial geoturístico na planície costeira do setor sudeste da Ilha do Maranhão. IV Simpósio Brasileiro de Patrimônio Geológico. Ponta Grossa. 2017. Disponível em: https://www.4sbpg.com/anais.

ROSS, J.L.S. Ecogeografia do Brasil: subsídios para o planejamento ambiental. Oficina de textos, 2006.

Serviço Geológico do Brasil. (CPRM). Geodiversidade do Estado do Maranhão. Programa Geologia do Brasil: levantamento da Geodiversidade. Teresina, Brasil. 2013.

Silva, M. da. R. e. Geologia da Folha AS-23, São Luís e parte da Folha AS-24, Fortaleza. MME - Ministério das Minas e Energia; DNPM - Departamento Nacional de Produção Mineral. Projeto RADAM. Levantamento de Recursos Naturais. vol. 3. Rio de Janeiro. 1973.

SILVA, Q. D. da. Mapeamento Geomorfológico da Ilha do Maranhão. Tese apresentada ao Programa de Pós-Graduação em Geografia da Universidade Estadual Paulista - Unesp. 2012.

Silva, Q. D. da. e Silva, E. V. da. Análise geoambiental: uma proposta de zoneamento da bacia hidrográfica do rio Tibiri, Ilha do Maranhão - Maranhão. Anais da IV Semana Universitária. UECE. 2010.
SOTCHAVA, Viktor Borisovich. Por uma teoria de classificação e geossistemas de vida terrestre. Universidade de São Paulo. Instituto de Geografia. São Paulo, 1978.

\section{AGRADECIMENTOS}

Os autores agradecem ao Laboratório de Geoprocessamento e Geografia Física (LAGGEF), do CERES-UFRN por estender suas instalações para que este trabalho fosse produzido e ao bolsista do referido

Recebido em: 11/09/2019

Aceito para publicação em: 17/04/2020 